\title{
Corrosion on prestressing wires due to segregation of the injection mortar - Detection of injection defects with Ultrasonic- Echo Technique
}

\author{
Christian Sodeikat ${ }^{1, *}$, Klaus Mayer $^{2}$, and Philipp Obermeier $^{3}$ \\ ${ }^{1}$ Engineering firm Schiessl Gehlen Sodeikat GmbH (SGS), 80687 Munich, Germany \\ ${ }^{2}$ University Kassel, 34199 Kassel, Germany \\ ${ }^{3}$ Engineering firm Schiessl Gehlen Sodeikat GmbH (SGS), 80687 Munich, Germany
}

\begin{abstract}
Unsuitable granulometry of injection mortar can promote segregation if high hydrostatic pressure impacts on the mortar for longer time during hardening. Endangered for segregation are long perpendicular prestressing tendons e.g. used in high towers due to the high hydrostatic pressure inside. The segregation causes an accumulation of water and solved ions on top of the tendons. In this area an extremely high $\mathrm{pH}$-value and a very low electrochemical potential occurs. This environment is extremely corrosive and can cause wire breaks within only few months. With the Ultrasonic-Echo Technique (Flaw Detectors) it is possible to detect injection defects by using the phase shift technique.
\end{abstract}

\section{CONSTRUCTIONS WITH PERPENDI- CULAR PRESTRESSING TENDONS}

High concrete towers often are prestressed in perpendicular direction. If the towers are made of precast elements the prestressing tendons ensure the stability because no reinforcement crosses the horizontal joints. The adhesive or connecting mortar in the joints has to even deviations and to seal the joints against water ingress.

After concreting or placing the precast elements the prestressing wires are pitched and prestressed. The mortar usually will be pressed from the bottom anchors to the top anchors. While reaching the top anchors the grouting process is stopped. If the mortar level sinks mortar is poured manually through holes in the top anchors.

Reinforcement steel and prestressing steel are passive in contact with alkaline cement materials. It is important that the prestressing steels are embedded completely in mortar and no defects like hollow zones etc. occur.

Recently broken prestressing tendons were observed in several constructions. Bertolini, L. et. al. (2011) report the case of a cable bridge where a prestressing cable broke after less than 2 years from construction. The engineering firm SGS examined wind energy towers where prestressing wires broke within only few months.

\subsection{Mechanism of the corrosion damage}

\subsubsection{Segregation of the injection mortar}

The length/height of the prestressing wires can reach $60 \mathrm{~m}$ and more. Therefor hydrostatic pressures inside the tendons of $12 \mathrm{~N} / \mathrm{mm}^{2}$ can occur until the setting process of the mortar begins.

The mortar is not a solution but a slurry of liquid and solid phases. The solid phases/particles with higher mass density sediment in dependency of the size and the density. Unsuitable grain size distribution of the injection mortar, high amounts of water and long setting times increase the risk and the amount of potential segregation. The same phenomenon can occur in long bore piles in dense ground like clay.

Injection cements with high fineness and a low effective grain diameter lower the tendency of segregation Hornung, F. (1986).

\subsection{Mechanism of the corrosion}

The opening of the tendons of the cable bridge showed zones where the injection mortar was segregated, Bertolini, L. et. al. (2011). These zones were found on the upper parts of the cables near the ends. The mortar was not grey and hardened correctly but showed a whitish colour and appeared as an unhardened plastic paste (Fig. 1). In zones with this paste heavy corrosion of the prestressing wires occurred while in zones with normally hardened mortar no corrosion could be observed (Fig. 2). 


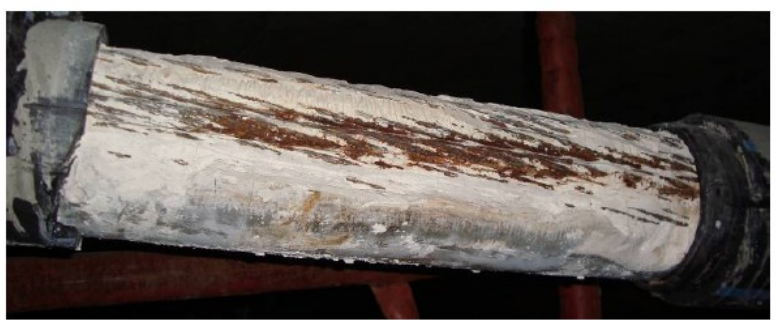

Fig. 1. Whitish segregated grout and corroded wires, figure 2 from Bertolini, L. et. al. (2011).

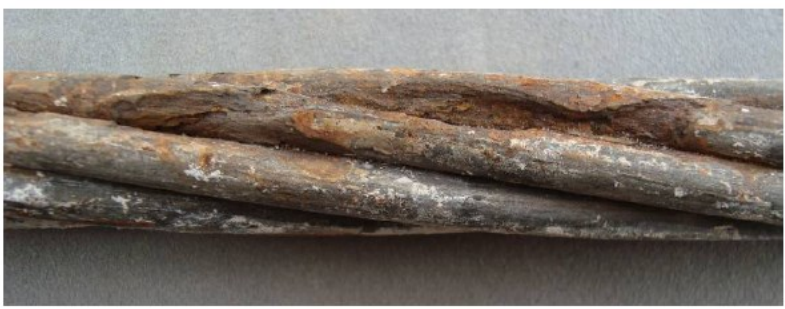

Fig. 2. Corrosion on a prestressing strand in contact with whitish segregated grout, figure 3 from Bertolini, L. et. al. (2011).

Due to Bertolini, L. et. al. (2011) the failure was ductile and not induced by hydrogen stress corrosion.

The chemical analysis of the whitish paste approved the segregation of the mortar. The comparison with the non-segregated mortar showed a concentration of alkalis and sulphate ions but no increased concentration of chlorides, Table 1.

Table 1. Analysis of non-segregated and segregated grout

\begin{tabular}{ccc}
\hline Type of grout & $\begin{array}{c}\text { Non segregated } \\
(\text { NS) }\end{array}$ & $\begin{array}{c}\text { Segregated } \\
(\mathrm{S})\end{array}$ \\
\hline $\mathrm{Al}_{2} \mathrm{O}_{3}$ & $1.61-2.47$ & $1.18-2.02$ \\
$\mathrm{CaO}$ & $39.6-47.2$ & $32.4-47.0$ \\
$\mathrm{~K}_{2} \mathrm{O}$ & $0.29-0.99$ & $0.66-4.00$ \\
$\mathrm{Na}$ & $0.27-0.63$ & $0.47-2.40$ \\
$\mathrm{MgO}_{2} \mathrm{O}$ & $1.28-1.95$ & $0.88-1.48$ \\
$\mathrm{Fe}_{2} \mathrm{O}_{3}$ & $1.13-2.27$ & $1.02-1.93$ \\
$\mathrm{SO}_{3}$ & $1.75-4.15$ & $3.58-7.88$ \\
Residue & $42.5-50.3$ & $46.2-51.2$ \\
\hline
\end{tabular}

The $\mathrm{pH}$-value of the whitish mortar was about 14.2.

The very high $\mathrm{pH}$-value in combination with the low electrochemical potential caused by the lack of oxygen was the reason of the severe corrosion attack. This corrosion mechanism was found by Pourbaix, M. (1974) and confirmed by Bertolini, L. et. al. (2011) in laboratory tests (Fig. 3).

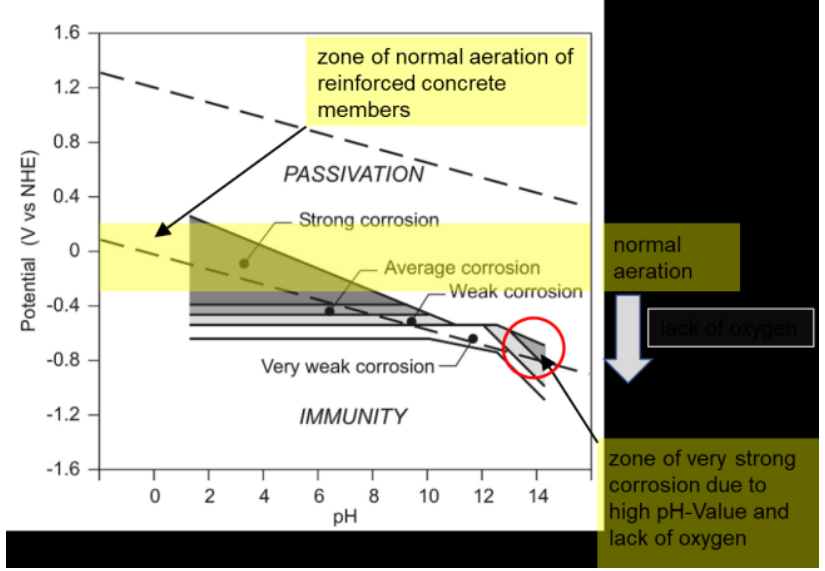

Fig. 3. Modified Pourbaix diagram. The circle shows a zone of very strong corrosion due to the lack of oxygen and a high $\mathrm{pH}-$ value Pourbaix, M. (1974)

\section{Investigations of prestressed concrete towers}

The owner of concrete towers observed broken prestressing strands only few months after construction. He commissioned us with the inspection on site to find out the reason of the failure and to check possibilities to detect defects in the prestressing tendons nondestructively (NDT-Methods).

Tests on site showed that many tendons had large areas at the top of the concrete sections where the injection mortar was segregated. In this area zones were located as well only filled with water. The endoscopy executed from the top anchors showed many broken wires (Fig. 4).

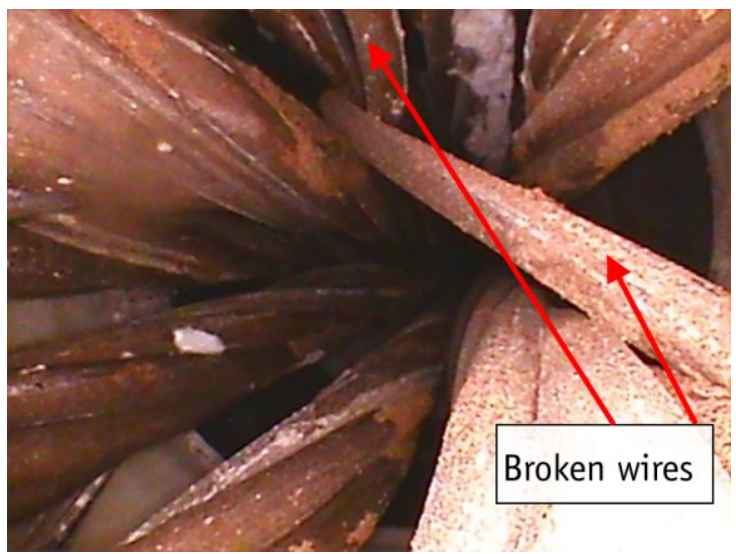

Fig. 4. Broken wires in the top zone of one strand. This zone was filled with water.

Beneath the water filled zone zones filled with very weak, wet and plastic mortar were present. With increasing distance from the top of the concrete section the mortar showed more and more less segregation until it was hardened and hydrated correctly. The length of the zones with segregated mortar were between some decimetres up to $10 \mathrm{~m}$. The segregated mortar had a grey, whitish, locally light yellow colour like the mortar of the cable bridge Bertolini, L. et. al. (2011), (Fig. 5, Fig. 6). 
The wires in the vicinity of the segregated mortar and in zones without mortar showed severe corrosion with losses of the cross section up to $20 \%$, many wires were already broken (Fig. 6, Fig. 7)

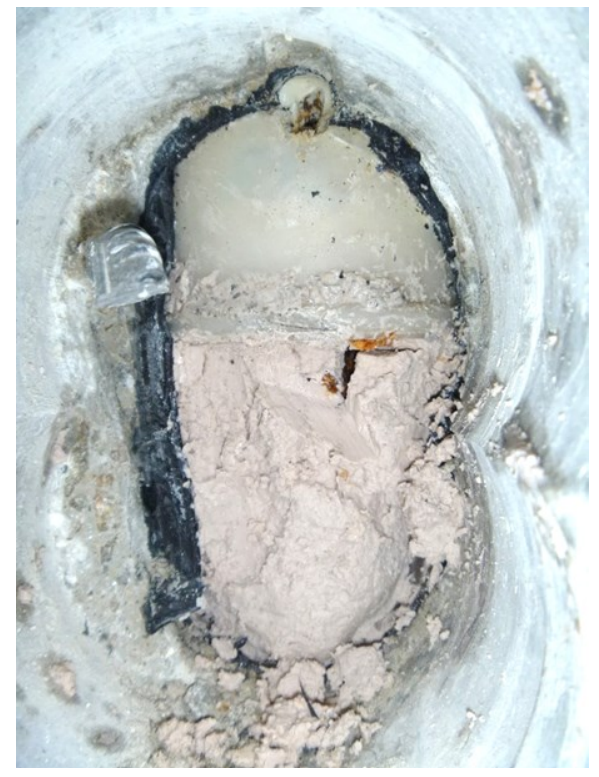

Fig. 5. Opened duct. The mortar was segregated, plastic, wet and whitish.

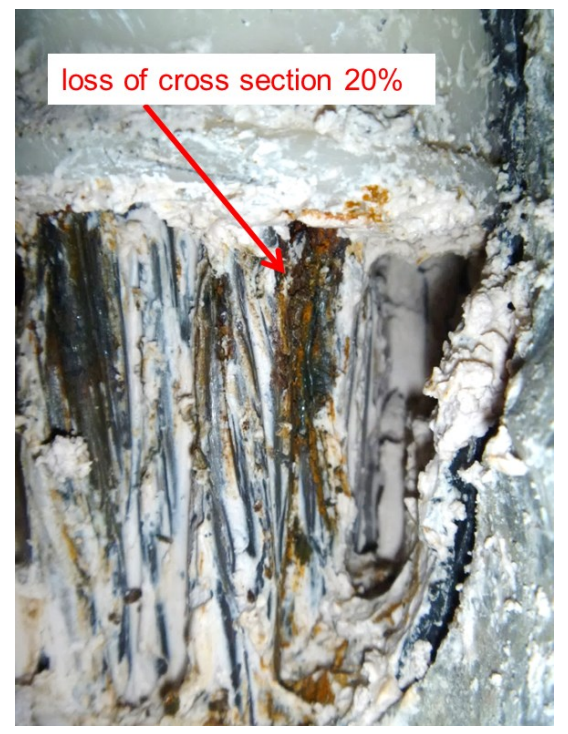

Fig. 6. Opened duct. The loss of cross section of some wires was about $20 \%$.

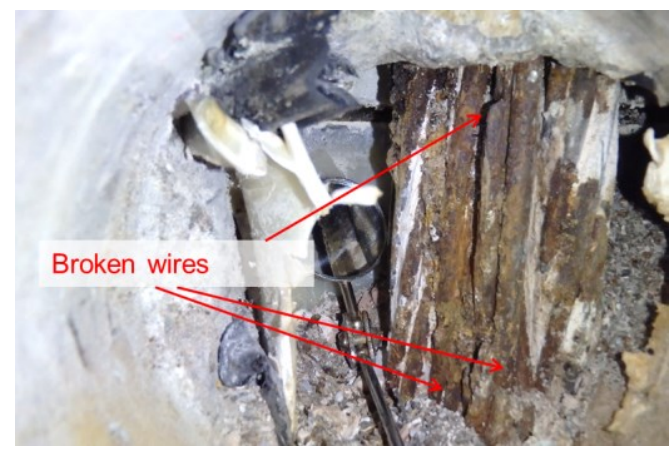

Fig. 7. Opened duct. Three wires of this tendons were broken.
The chemical analysis showed that the mortar was segregated extremely. There were high amounts of sulfate, $\mathrm{Na}_{2} \mathrm{O}$ and $\mathrm{K}_{2} \mathrm{O}$ corresponding with a high $\mathrm{pH}$ Value (Table 2). It has to be assumed that the potential was low due to the lack of oxygen inside of the dense duct. The corrosion conditions of the prestressing steel in contact with the segregated mortar were as severe as observed in the cable bridge tested in Bertolini, L. et. al. (2011).

Table 2. Chemical analysis of the segregated mortar.

\begin{tabular}{|c|c|c|}
\hline \multirow{2}{*}{ Ions } & $\begin{array}{c}\text { Segregated } \\
\text { mortar }\end{array}$ & $\begin{array}{c}\text { Non } \\
\text { segregated } \\
\text { mortar }\end{array}$ \\
\cline { 2 - 3 } & \multicolumn{2}{|c|}{ Mass.-\% } \\
\hline $\mathrm{SO}_{3}$ & 9.4 & 2.1 \\
\hline $\mathrm{Cl}$ & $<0.01$ & $<0.01$ \\
\hline $\mathrm{NaO}_{2}$ & 1.4 & 0.12 \\
\hline $\mathrm{K}_{2} \mathrm{O}$ & 13.4 & 1.25 \\
\hline $\mathrm{NaO}_{2 \text { eqiv. }}$ & 10.2 & 0.95 \\
\hline $\mathrm{CaO}^{*}$ & 31,3 & 52.6 \\
\hline
\end{tabular}

\section{Locating injection defects with the Ultrasonic-Echo Technique}

To ensure the durability of the construction it was necessary to find potential zones with segregated mortar respectively with high risk of corrosion and wire breaks. To minimize the testing effort and damaging the construction we tested the possibility to detect injection defects with the Ultrasonic-Echo Technique.

\subsection{Low-Frequency Ultrasonic Echo Technique}

Low-frequency Ultrasonic-Echo Technique is based on the emission of mechanical waves (ultrasonic waves) into the components which have to be inspected. Ultrasonic waves are reflected on bounding surfaces with a change of the acoustic impedance. Depending on whether the subsequent acoustic impedance is higher or lower, a phase shift will occur or not. With increasing run length of the mechanical ultrasonic waves an increasing loss of energy occurs. This limits the possible measuring depth. Similar to the radar technique high frequencies enable high resolution. The wave length has to be bigger than the size of the aggregates of mortar or concrete, otherwise only the subsurface aggregates can be detected. That means that the resolution of measurements of concrete is limited a priori. 
The surface of the measuring components has to be sufficiently even and sound to couple the mechanical probes for inducing the ultrasonic waves (Fig. 8).

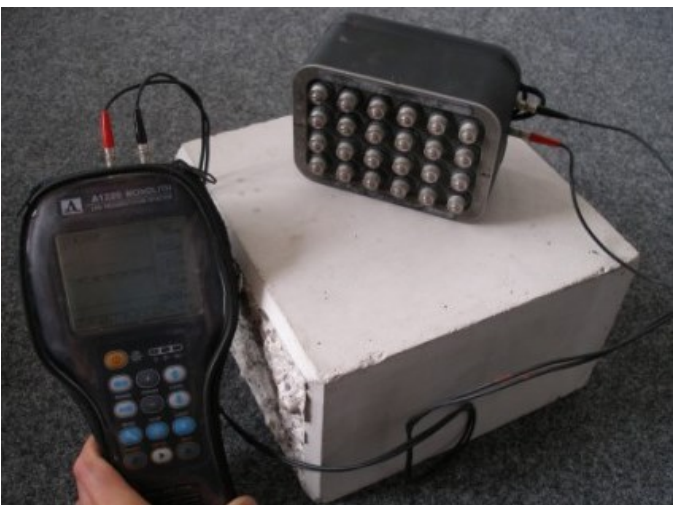

Fig. 8. Low-frequency Ultrasonic-Echo device with 24 point contact probes

To detect inner elements like anchors, prestressing tendons, reinforcement, defects like delaminations, hollow zones etc. or to determine the thickness of concrete elements low-frequency flaw detectors with multi probe arrays are suitable Sodeikat, Ch. (2012, 2016), (Fig. 8, Fig. 9).
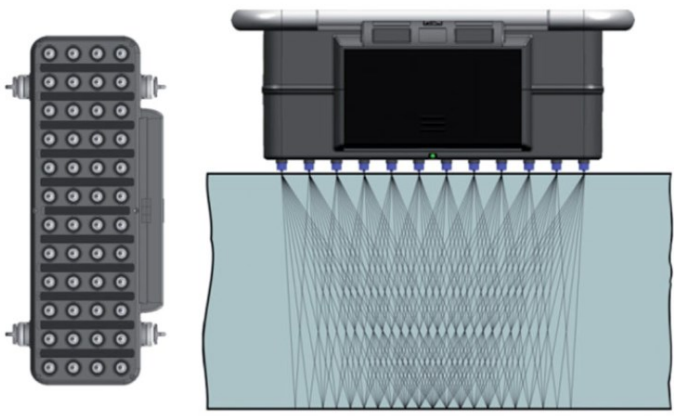

Fig. 9. Downside view of a linear array including 12 probe rows. Sound paths of a multistatic measurement (simplified) (rights: ASC Ltd. Moscow).

To detect deep lying elements and to get better 3Dresolution ultrasonic tomographs are often more suitable than common flaw detectors. To use the method Phase Shift Analysis, cp. next chapter, Ultrasonic tomographs should be used (Fig. 9).

The probe lines of the tomograph shown in fig. 9 are sending and receiving alternating.

All US-devices with contact probes are using shear waves. This is advantageous because no coupling agents like water filled diaphragms or clay etc. are necessary. The particularity of this wavetype is the total reflection of the wave at the transition to air.

\subsection{Method of Phase Shift Analysis}

If the subsequent acoustic impedance of a material is lower theoretically no phase shift of the ultrasonic waves (phase shift angle $0^{\circ}$ ) will occur at the boundary/interface (Fig. 10). This is the case when the edges/backwalls of concrete members are detected concrete has a higher acoustic impedance than air.

In contrast if the subsequent acoustic impedance of a material is higher theoretically a phase shift of $180^{\circ}$ will occur (Fig. 10). This is the case when inside of concrete members built-in parts of steel or for example prestressing wires are located.

The relationship mentioned above is valid for reflections where parts of the waves penetrate and interfere with inner reflections. In practice due to the limits of the devices and interferences the angles are between these extreme values. The appearance of a phase shift at the boundary/interface high-impedance/low-impedance or low-impedance/high-impedance is primarily depending on the properties of the probes and parameters of the imaging algorithm concerning filtering and deconvolution. In diagrams the values of the phase shift can be displayed as colour wheels, Schulze, S. et. al. (2013). To analyse the phase shift a special software tool is required. For more information see Patent application DE 102006027 132.7.

Fig. 11 and Fig. 12 show an arithmetical simulation of the reflections of a non-grouted tendon and a sufficiently grouted tendon.

\section{Measurement principle}
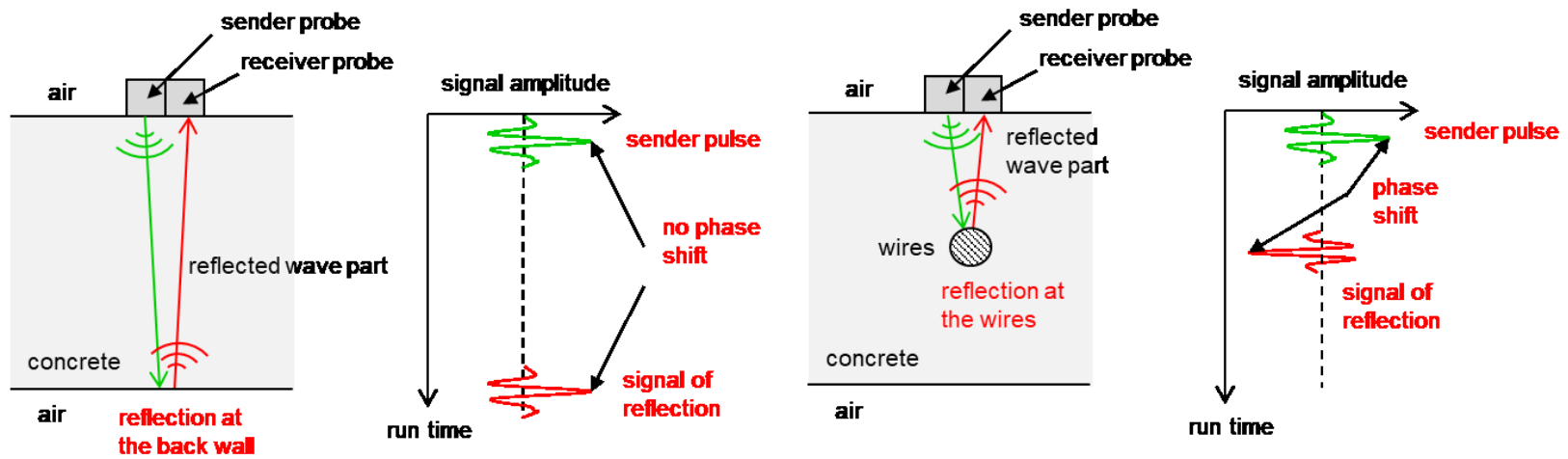

Fig. 10. Measurement principle and phase shift of the reflected waves due to the acoustic impedance at the boundary/interface 


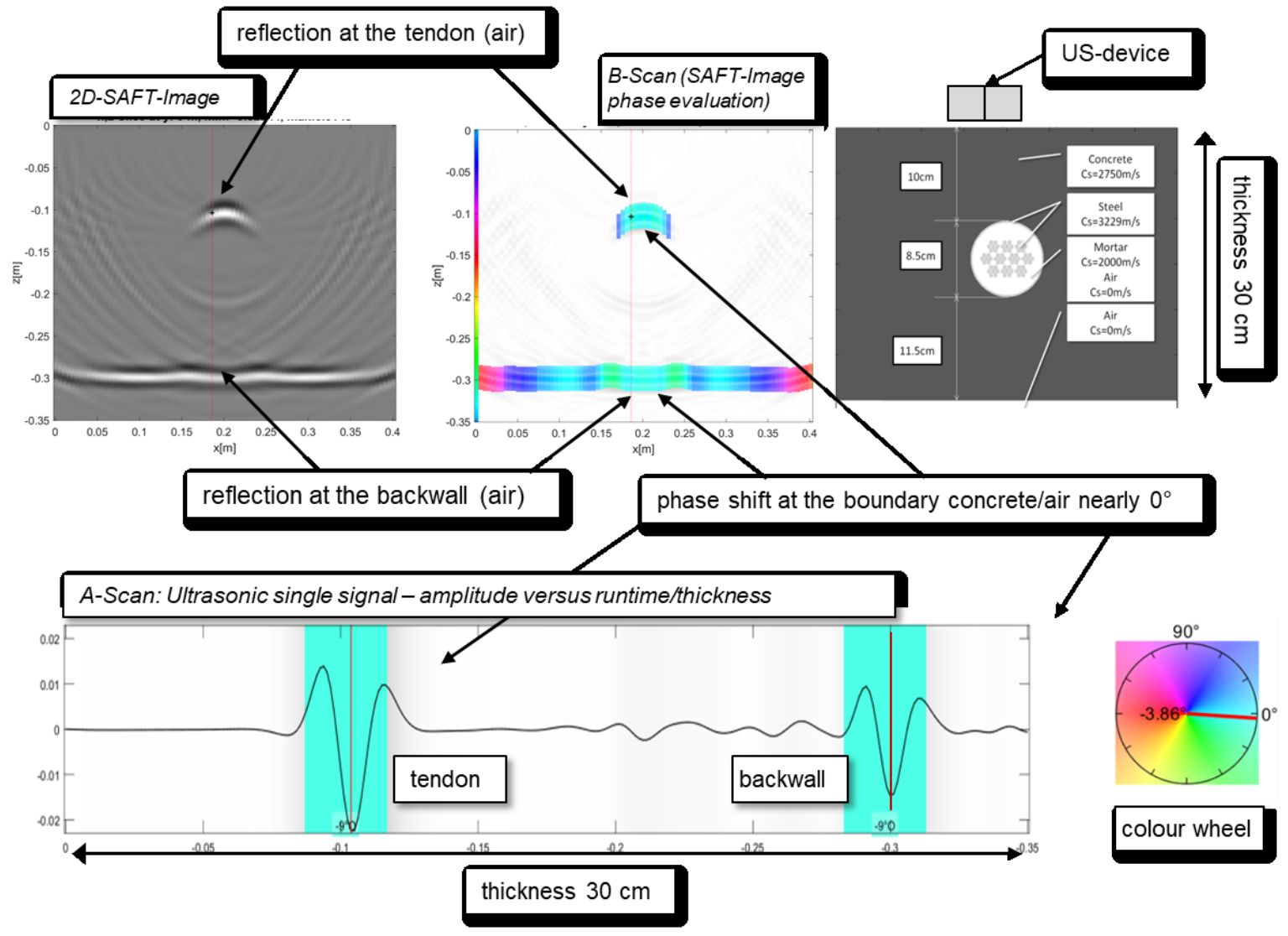

Fig. 11. Cross section: Arithmetical simulation with InterSAFT of a non-grouted tendon. The phase shift at the boundary/interface concrete/air is nearly $0^{\circ}$.

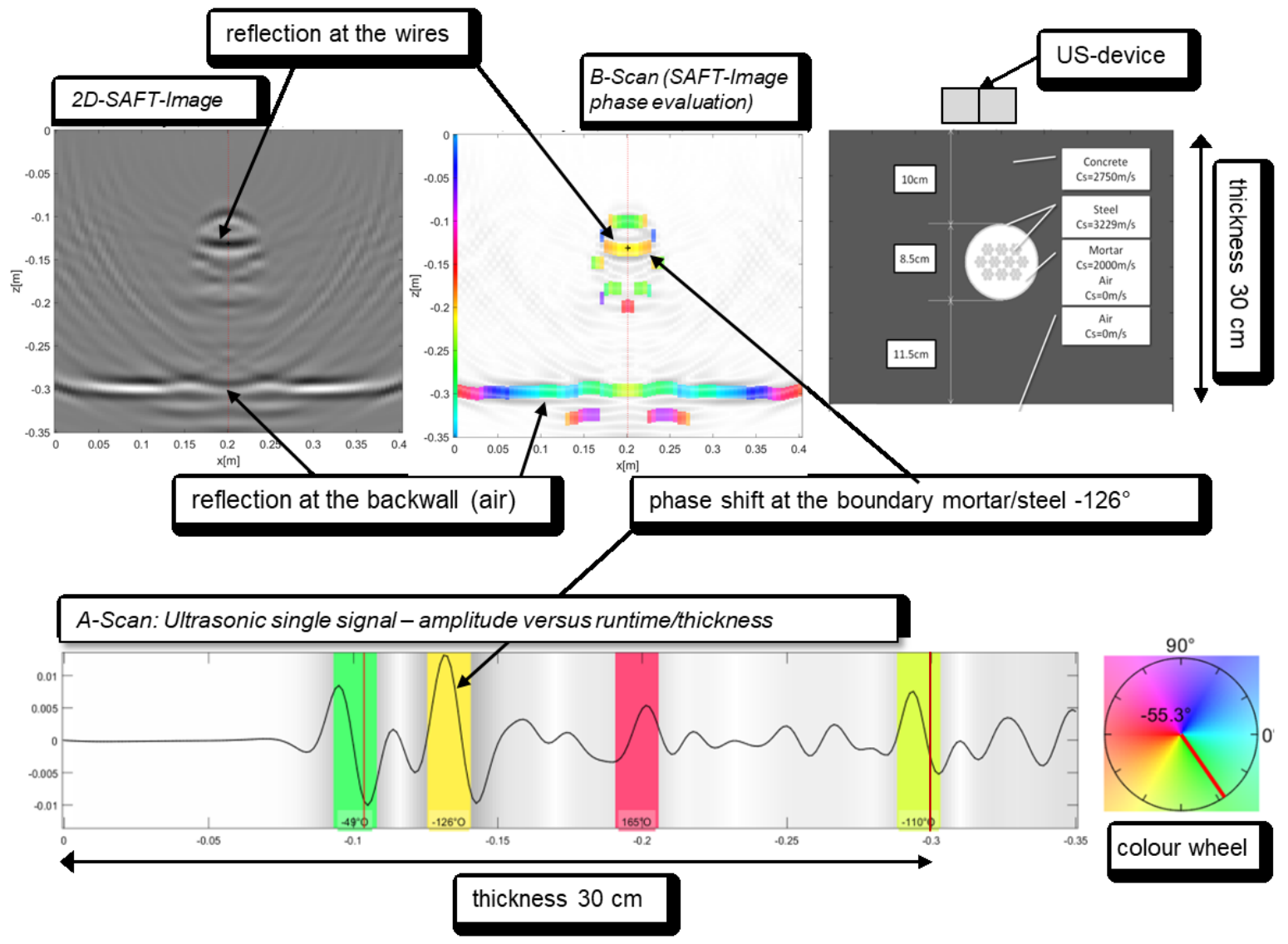

Fig. 12. Cross section: Arithmetical simulation with InterSAFT of a sufficiently grouted tendon. The phase shift at the boundary/interface mortar/steel is $-126^{\circ}$. 

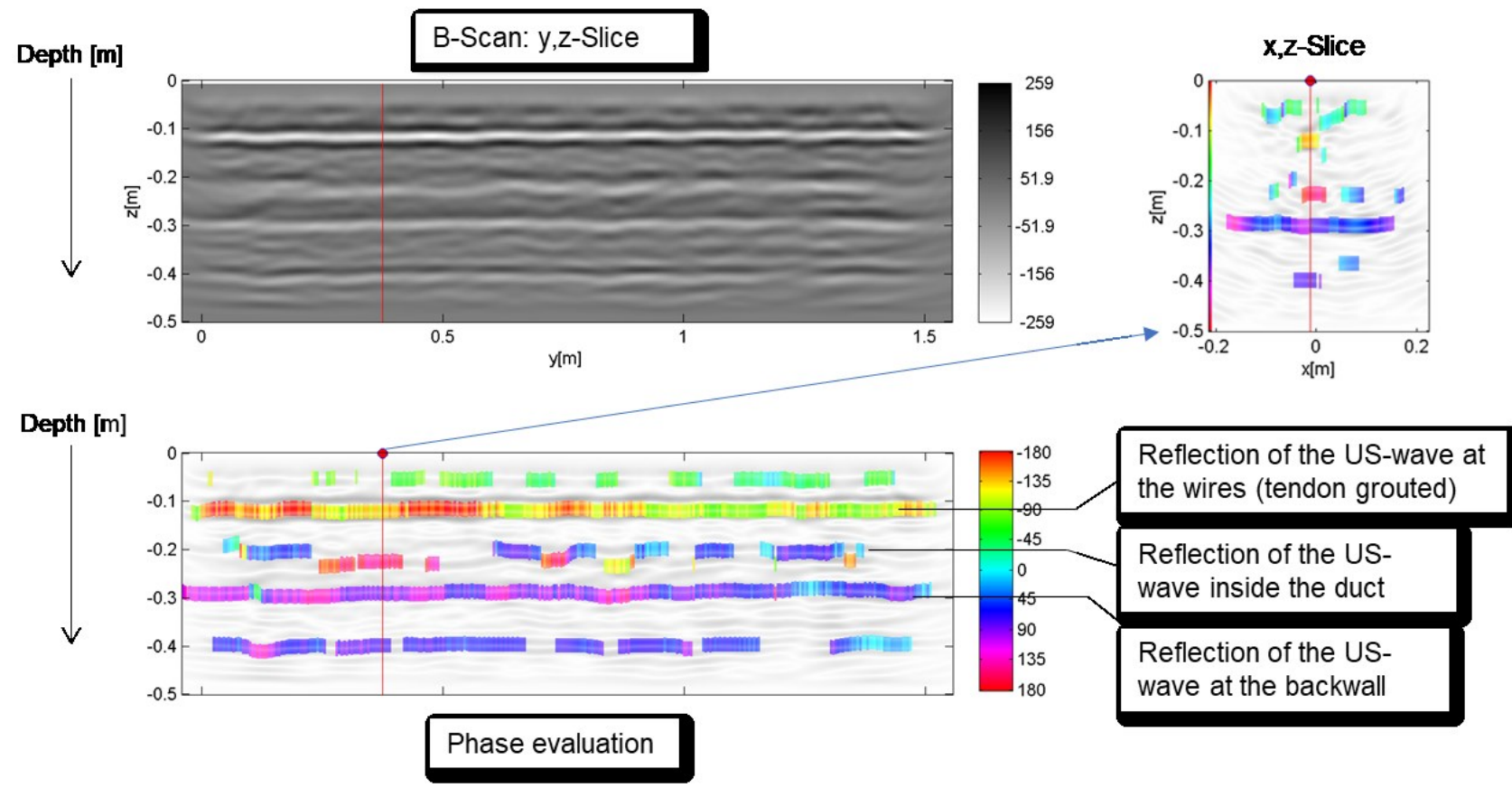

Fig. 13. Longitudinal section: Test signals of a sufficiently grouted tendon ; US-Signals (top), phase shift analysis (bottom)

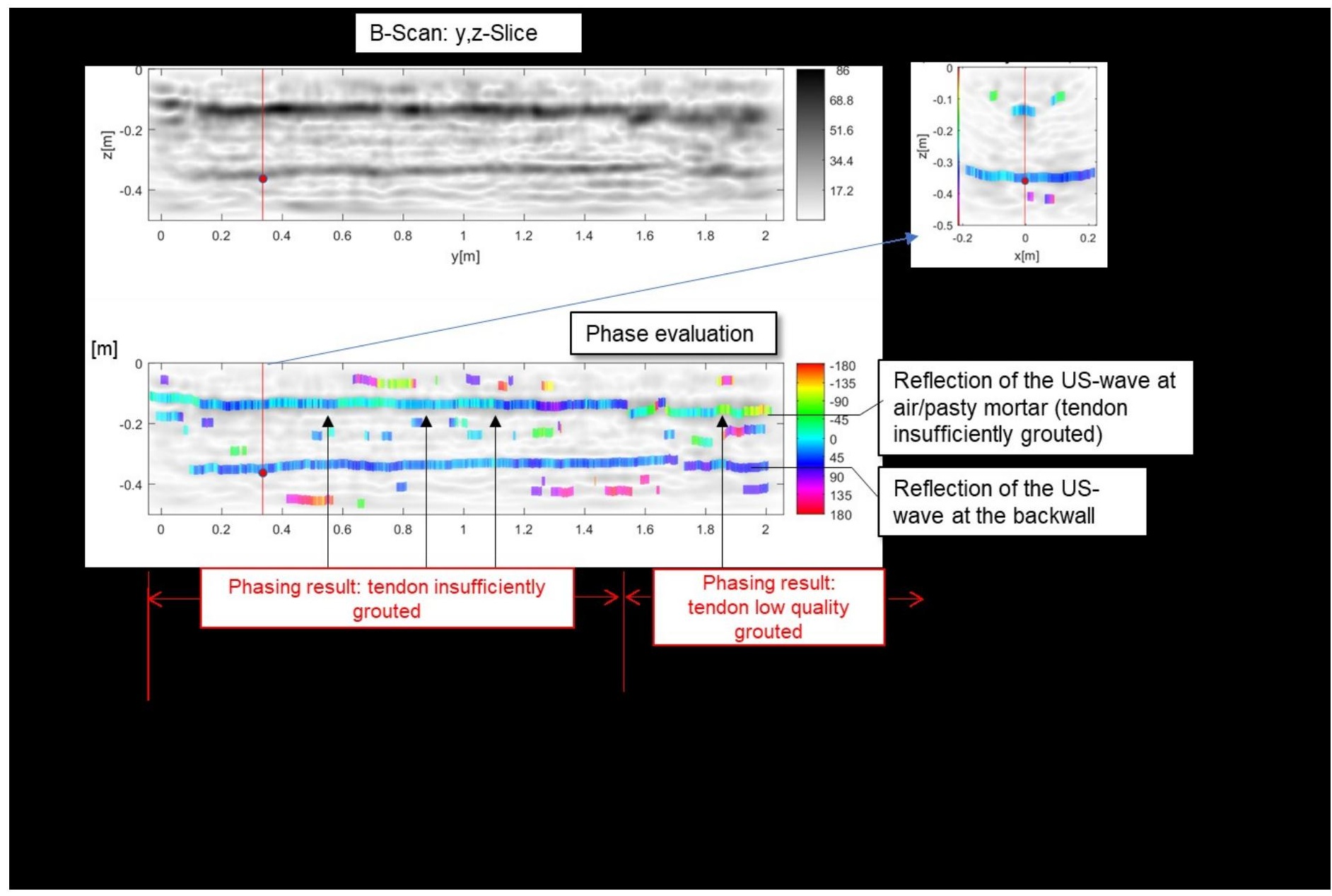

Fig. 14. Longitudinal section: Test signals of an insufficiently grouted tendon ; US-Signals (top), phase shift analysis (bottom) 


\subsection{Testing campaign on site}

For locating the tendons measurements with Impulse Radar devices and reinforcement scanners were executed. This is advantageous because testing with these techniques is faster due to the contactless testing method. Contrary to this US measuring always needs a direct contact to the surface.

For analysing the phase shift of US signals a 2D measuring grid on the surface of the tested concrete members is needed. The distance of the testing points shall not be bigger than $2 \mathrm{~cm}$. To get accuracy results it is important that the distances are met very precisely.

To ensure a high precision if the US signals the Ultrasonic tomograph A1040Mira, Acoustic Control System Ltd. was used. This device has 48 sender and receiver probes which send and receive alternately.

For analysing the US signals the software tool InterSAFT (interactive synthetique aperture focus technique) created at the University of Kassel was used Patent application DE 102006027 132.7.

The test results showed that in zones with defect-free grouting and sound mortar a phase shift around $-90^{\circ}$ to $-180^{\circ}$ occurred (Fig. 12). In zones without mortar the phase shift was between $0^{\circ}$ and $110^{\circ}$ (Fig. 13). In zones where the tendon was low quality grouted the phase shift was between $0^{\circ}$ and $-90^{\circ}$ (Fig. 13).

\section{Conclusion}

Prestressing wires of some concrete towers have been broken only few months after construction due to severe corrosion. Tests on site showed that the injection mortar was segregated caused by high hydrostatic pressure inside the tendons and an unsuitable granulometry of the injection cement. The segregated mortar had very high $\mathrm{pH}$-value due to the concentration of alkalis and a high amount of sulphate. The wires showed a low electrochemical potential due to the lack of oxygen. Under these conditions heavy corrosion is induced, which also could be shown on a cable bridge in Italy few years ago.

Tests on site with the Ultrasonic-Echo technique showed that zones with defects of the injection inside the ducts can be detected. The testing campaign was executed with US-Array and tomograph devices with contact probes using shear waves. The analysis of the US signals was executed with the method of the phase shift analysis using the software tool InterSAFT.

\section{References}

Bertolini, L., Carsana, M.: High pH Corrosion of Prestressing Steel in Segregated Grout, In: Andrade C., Mancini G. (eds) Modelling of Corroding Concrete Structures. RILEM Bookseries, vol 5. Springer, Dordrecht.

Hornung, F.: Vorgänge im Frischbeton bei der Entwässerung unter hohem Druck. Dissertation at Technical University of Munich, centre of building materials, Feb. 1986

Pourbaix, M.: Atlas of electrochemical corrosion, $N A C E$ (1974).

Sodeikat, C.: Structure testing with Ultrasonic-Echo and Impulse Radar Technique, Proceedings of the $3^{\text {rd }}$ ICCRRR 2012 Cape Town

Sodeikat, C.: Application Limits of NDT Methods fpr Reinforced and Pretsressed Concrete Members in Practice, BOOK of ABSTRACTS, $19^{\text {th }}$ WCNDT, 2016 Munich.

Schulze, S., Mayer, K., Krause, M.: Investigation of prestressed concrete using the imaging ultrasonic echo method, Beton- und Stahlbetonbau 108 (2013), issue 12

Patent application DE 102006027 132.7: Verfahren zum Detektieren von Fehlstellen in Betonbauteilen 